\title{
Code Alternation Patterns in Bilingual Family Conversation: A Conversation Analysis Approach
}

\author{
Marianthi Georgalidou, ${ }^{\mathrm{a}}$ Hasan Kaili, ${ }^{\mathrm{b}}$ and Aytac Celtek ${ }^{\mathrm{c}}$ \\ a) University of the Aegean \\ georgalidou@rhodes.aegean.gr \\ b) University of the Aegean \\ kaili@rhodes.aegean.gr \\ c) University of the Aegean \\ celtek@aegean.gr
}

\begin{abstract}
In this study, we examine aspects of the overall organization of bilingual conversation during talk-in-interaction among members of a close-knit family network. Code Alternation ${ }^{1}$, prototypically seen as the contiguous juxtaposition of semiotic systems in such a way that the participants interpret the juxtaposition as such (Auer 1995, 116), is a common conversational practice in bilingual communities. Taking a Conversation Analytic approach as our point of departure, we analyze code alternation and code-mixing practices in naturally occurring conversations among family members of the bilingual in Greek and Turkish Muslim community of Rhodes. Firstly, we examine Greek/Turkish alternation as a conversational strategy with clear discourse functions (Auer 1995; 1998). Secondly, we see non-prototypical instances of the use of both languages in the same conversation as instances of medium negotiation or a mixed-code choice on the part of the participants (the bilingual medium or the monolectal view of code-switching, Meeuwis and Blommaert 1998; Auer 1998; Gafaranga 2007a). Last, we examine issues of identity as these can be approached based on the choices speakers of different age groups make during interaction. Based on the analysis, it is shown that, a) code alternation practices reflect not only aspects of the politics and management of the identity of the speakers as members of the same ethnic category, but also broader issues concerning the construction of youth identities as opposed to those of older generations, and b) data coming from diverse bilingual communities point to the need for greater clarity in the proposed models for the analysis of code alternation patterns.
\end{abstract}

\section{Keywords}

Bilingual conversation, Code alternation patterns, Code-switching, Conversation Analysis, Greek/ Turkish alternation, Identity construction

${ }^{1}$ Code alternation is used here as a cover term for code-switching and transfer within bilingual conversation. 


\section{Introduction}

In this study, we analyze conversations recorded during ethnographic research in the bilingual in Greek and Turkish Muslim community of Rhodes within a CA framework. Our data comprise recordings of everyday talk-in-interaction during bilingual family gatherings. We examine aspects of the overall and sequential organization as well as issues of identity as these can be approached based on the code alternation choices speakers of different age groups make during interaction.

Bilingual conversation and code alternation, or else conversational codeswitching (Wei 2005) have become major issues, especially in what is defined as the socio- and pragmatic approaches to the field. Bilingualism, firstly seen as a marginal social phenomenon, has proven a universal aspect of the linguistic reality of most of the world's speech communities. In the context of contemporary linguistics and in particular, in the context of the sociolinguistic and pragmatic approaches to actual language use, the study of bilingual conversation has altered the way we approach and evaluate phenomena such as the use of two (or more) languages by participants in the same communicative event, i.e. talk-in-interaction. First seen as a non-systematic and rather problematic phenomenon concerning the communicative competence of bilinguals -or the lack of it- (Gafaranga 2007b), talk in more than one language has now gained a prominent place within socio- and pragmatic approaches to everyday talk.

Following Fishman's well-known study of the domains of language behaviour $(2000,92)$, a number of sociolinguistic and ethnomethodological approaches have shed light on different aspects of bilingual conversation ${ }^{2}$. Among them, the most influential to contemporary discussion are those of Blom and Gumperz 1972 and Gumperz 1982, the Interactional Sociolinguistic approach to "wel they codes"; Myers-Scotton 1988 and Myers-Scotton and Bolonyai 2001, the markedness model; Auer 1984, 1995, 1998, 2005, Torras and Gafaranga 2002 and Gafaranga 2007a and b, the ethnomethodological, conversation analytic approaches to code alternation patterns (for a review of the relevant literature also see Gafaranga 2007b).

Within the scope of Interactional Sociolinguistics, Gumperz (1982) sees code alternation as a contextualization cue signalling contextual information equivalent to what in monolingual settings is conveyed through prosody or

2 There is extensive literature dealing with structural and grammatical aspects of codeswitching to which we are not going to refer as it exceeds the scope of this paper. 
other syntactic or lexical processes $(1982,66)$. He also sees minority languages as the we-codes which become associated with in-group and informal activities and majority languages as the they-codes, associated with more formal and less personal out-group relations $(1982,66)$.

Myers-Scotton's markedness model sees cases of code-switching as unmarkedmarked choices within rights and obligations (R/O) sets (Myers-Scotton 1988). She claims that speech community members have a sense of "script", one that permits a fit between language choice and the rights and obligations set, language choice being unmarked when there is congruence between the two and marked when there isn't. She also claims that speakers have a natural theory, i.e. mental representations of markedness that allows the distinction between marked and unmarked code choices (1988, 152).

Both models, however, despite illuminating crucial aspects of bilingual communication, have difficulty accounting for cases of non-straightforward correspondence between language choice and social norms (for example, local processes of discourse organization, the case of not being able to determine a base language against which alternation becomes meaningful, or cases where a monolectal operation of switching seems to be at work (Meeuwis and Blommaert 1998). As Auer (1984) and Wei (1998) point out, both models "bring along" ideas about macro-societal values of language use and predominantly refer to external constraints on linguistic choice. In an attempt to overcome such restrictions, the CA approaches discussed below (section 1.1) aim at shifting attention from "brought along" to "brought about" aspects of bilingual communication, allowing for the grounding of structures in practices and vice versa.

\subsection{Conversation Analytic approaches to code alternation and their impact on the discussion of issues of identity}

Code alternation has been extensively examined as a structural and a social phenomenon both for the constraints that are said to determine its intrasentential use, and for issues of ideology and identity in relation to why and how speakers choose it as a communicative strategy. Nevertheless, as Wei (2005) convincingly points out, code-switching is essentially a conversational activity. As a consequence, the starting point of any meaningful analysis of such an activity must be its location in the conversational context in which it takes place $(2005,276)$.

Prototypically, code alternation is defined as "a relationship of contiguous juxtaposition of semiotic systems, such that the appropriate recipients of the resulting complex sign are in a position to interpret the juxtaposition as 
such" (Auer 1995, 116). However, code alternation exceeds the limits of this definition, as juxtaposition may not always be meaningful at the local level of the conversational episode as far as the immediate action is concerned. The location of variable alternation patterns within bilingual interaction therefore calls for an organizational account of the relevant conversational structures, as well as an overall approach to the orderliness of bilingual conversation. Ethnomethodology and Conversation Analysis (henceforth CA), a framework that sees talk as practical social action in its own right (Atkinson and Heritage 1984), has a considerable number of advantages in this respect. To begin with, it places conversation at the center of attention as the ultimate locus of language choice and use. Seeing talk as a social activity that is primarily meaningful for the participants themselves, CA adopts the emic perspective towards language use, that is, the speakers' own perspective of the sequential structure of talk. Despite the fact that "partial autonomy" of the conversational level (Auer 1998, 4) may be implied by such an approach, the indexicality of code alternation patterns provides insights both on the organizational aspect of conversation -the micro level of discourse organizational switching- and the macro dimensions of participant related switching that is relevant to matters of preference and identity construction processes, as well as issues of societal norms. Within the Ethnomethodological/CA approach, two organizational accounts (Gafaranga 2007a, 297) for the analysis of patterns of alternation within bilingual conversation have been proposed, namely the model examining the local order of talk through four patterns of alternation (Auer 1984, 1995) and the model proposed by Gafaranga (Torras and Gafaranga 2002; Gafaranga 2007a and b) focusing on the overall organization of talk.

As far as Auer's discussion of code alternation phenomena is concerned, four patterns of conversational code alternation have been proposed (Auer 1984; 1995) that distinguish between discourse related and participant related alternation. In Pattern I, Auer sees switching from code A to code B between utterances or in the same utterance as the discourse related alternation or code alternation as a contextualisation cue (Gumperz 1982), marking shifts in topic, preference structures concerning preferred/dispreferred speech acts, participant constellation dynamics, insertion sequences and the organization of narrative. In Pattern II, the participant related alternation, participants switch from code A to code B repeatedly until consensus is reached over the medium of conversation. This is the language preference related switching that activates the process of language negotiation, which leads to the prevalence of one language over another. Pattern III, re-assessed in Bilingual Conversation Revisited by Auer himself (1998), is considered a discourse related code alternation choice that does not permit the identification of any of the 
languages used as the base language of the interaction. It is a rather debatable case of alternation as it raises the question of a single bilingual medium as part of the overall organization of the interaction over the juxtaposition of two distinct linguistic systems. Pattern $I V$, the intrasentential momentary switching that does not change the language of the interaction, is defined as transfer and is considered a participant related alternation pattern.

Gafaranga (2007a), and Torras and Gafaranga (2002) propose a revised model of bilingual talk-in-interaction and code alternation patterns that sees alternation as an aspect of the overall organization of bilingual conversation. The more significant contribution of the model to the present discussion is the shift from the entity language to that of medium, be it monolingual or bilingual, as the central unit against which the discussion of code alternation practices can be placed. The shift of attention from the juxtaposition of two languages to the overall conversational organization, and the potential of the bilingual medium of being part of this organization, permits a more synthetic view of code alternation within a continuum of prototypical to less prototypical code alternation patterns. However, the selection of a mixed code (Auer 1998,16 ) or the bilingual medium (Gafaranga 2007a) as an unmarked (neither repairable nor negotiable) choice in the interaction raises issues as to the meanings it brings about concerning the participants.

We see both models discussed so far as complementary, and we attempt to highlight aspects of the proposed analysis that are in need of further elaboration $^{3}$, the most prominent being the choice of the bilingual medium as part of the overall organization of bilingual interaction that may not be based on preference for a same medium talk (Gafaranga 2007a, 305). The emergence of systematic new ways of speaking that are neither standard nor monolingual varieties, and even exceed the limits of same medium preference as an interpretation scheme (as shown in section 4.3), leads to an extensive discussion of identity construction practices. The kind of social identities that the alternating use of distinct codes is an index to, as well as the relevance of such interpretations (Auer 2005) raise both theoretical and methodological issues that are related to bilingual interactive practices. Undoubtedly, code-switching, a language style in itself, indexes some kind of social membership beyond the membership indexed by the monolingual varieties involved in language alternation (Auer 2005; Wei 2005, 278).

${ }^{3}$ Still, as Auer (2005) points out there is a lot of comparative work to be done before a typology of code-switching and mixing styles stops being "a desideratum of research", as different groups and generations of bilingual speakers have developed different ways of mixing and switching (Auer 2005, 406). 
Nevertheless, identity issues raised by bilingual conversational choices, as for example the unmarked use of distinct codes by different speakers in the same interactive episode as the overall organizational pattern of talk, exceed the limits of ethnicity, or even "hybrid" ethnic equations, and concern variable aspects of claiming participation to different social groups and generations of speakers.

Taking the considerations discussed so far as our point of departure, we analyze conversations recorded during ethnographic research in the bilingual in Greek and Turkish Muslim community of Rhodes within a CA framework. Our data comprise recordings of everyday talk-in-interaction during bilingual family gatherings among members of a close-knit family network. We examine aspects of the overall and sequential organization of bilingual conversations, attempting a micro-macro link between conversational practices and ethnographically documented structures of the community, namely community networks (Gumperz 1982; Milroy and Wei 1995). Based on the analysis, we examine issues of identity connected to the code alternation choices speakers of different age groups make during interaction. Code alternation practices that distinguish different generations of speakers, reinforced by teasing and humor practices (Attardo 2001; Archakis and Tsakona 2005; Lytra 2007), point to the construction of individual and collective identities that go beyond the identity of the speakers as members of the same ethnic category, and raise issues that concern the construction of youth identities as opposed to those of older generations of speakers, which we discuss in the subsequent sections.

\section{The community}

Conversational episodes discussed in the present study come from a bilingual in Greek and Turkish Muslim community which historically resides on the island of Rhodes/ Greece for many centuries. Muslims of Rhodes are therefore, Greek citizens of Turkish origin who, within a historical context of succession to the distribution of power, as well as a recent context of actual and potential conflict with a neighbouring country with whom the community is indirectly connected, have lived on Rhodes since 1522. As far as the recent past is concerned, in 1912, during the Italian occupation, and then again after the annexation of Dodecanese islands to Greece in 1947, the community underwent a major shift as far as power distribution is concerned. After being the dominant group during Ottoman times, they acquired the unofficial status of a minority community. 
Although they were not deemed as covered by the Treaty of Lausanne, after the annexation of the Dodecanese islands in 1947, special status was acknowledged to the community as far as the Vakf ${ }^{4}$ and education were concerned. Nevertheless, the teaching of the Turkish language in Muslim schools was de facto abolished in 1972, and Muslim students of Turkish origin have attended monolingual state schools ever since. Nowadays, the Turkish language is mainly used within the community, as it is not formally taught or used in transactions with the Greek-speaking majority neither in formal nor in informal contexts. As a consequence, over the last 60 years almost the entire Muslim community (estimated population is $2500-3000$ people on the island of Rhodes) has shifted from near monolingualism in Turkish to bilingualism in Turkish and Greek.

As far as the linguistic repertoire of the community is concerned, older speakers use a Greek contact vernacular (Winford 2003, 236), based on the local Greek dialect of Rhodes with substantial interference ${ }^{5}$ from Turkish. Later generations use a variety of Greek with less interference. This interference is gradually fading away to the near or completely native Greek varieties of younger generations (Georgalidou, Spyropoulos and Kaili forthcoming). The shift towards native Greek varieties in urban settings precedes the shift in suburban and rural settings by one generation. (Georgalidou, Spyropoulos and Kaili forthcoming). There are different proficiency levels in Turkish as well. Most members of the grandparent and parent generation are fluent in the local variety of Turkish, whereas contact with standard Turkish is mainly accomplished through television and occasional visits to Turkey. The local variety of Turkish also exhibits substantial interference from Greek (Kaili et al. 2009).

\section{Research procedure}

Based on the theoretical assumption that it is possible to combine ethnographic data collection procedures with a CA framework, provided that an

\footnotetext{
${ }^{4}$ A vakf (waqf in Arabic and vakıf in Turkish) is an inalienable religious endowment in Islam, typically denoting a building or plot of land for Muslim religious or charitable purposes. It is conceptually similar to the common law trust.

5 The term interference used here strictly refers to structural convergence that leads to the rearrangement of phonological and morphosyntactic material because of diffusional interference that makes structures of the recipient language more similar to those of the source language (Heath 1984; Winford 2003). Interference phenomena in our material affect both languages (the local varieties of Turkish and Greek) of the community under study.
} 
emic- perspective is preserved over the informal community organization (Milroy and Wei 1995), we examine a close-knit community family network residing in a suburban settlement a few kilometres away from the city of Rhodes. We use ethnographic data collection procedures which allow us to obtain a realistic picture of patterns of language use as well as patterns of the informal social organization and their impact on the linguistic repertoire of the community. Research has been going on for more than six years. Recordings include both informal interview situations and naturally occurring conversations.

The excerpts analyzed for the present study come from one particular conversation during a dinner gathering that was recorded in June 2009 and comprise approximately 1 hour of talk $\mathrm{k}^{6}$. Therefore, they are natural occurrences of everyday family talk-in-interaction. They were recorded by one of the family members without the presence of the researchers. In the particular community network under study, dinnertime is an everyday social event during which family members, and occasionally people related to the family, gather together to share not only a meal but mostly talk over incidents that have already taken place or will take place in the near future. It is an important social event that aims at preserving the close-knit structure of the family, as it gives family members the opportunity to get together, share experiences and opinions, argue and tease each other. As this social practice is attended by family members of all age groups, it is an excellent opportunity to collect recorded conversational data that allows the comparative examination of linguistic choices of different generations of speakers. The aim of the present recordings, therefore, was to collect linguistic data that would allow the analysis of code-choice and code alternation patterns used by community/family members who belong to different age groups and relate them to issues of identity construction processes as these are exhibited in the everyday conduct of the members themselves.

\subsection{The participants}

The seven participants in the event under discussion are members of a closeknit community network residing in a suburban settlement a few kilometres away from the city of Rhodes. They reside in an area that has traditionally

\footnotetext{
${ }^{6}$ Altogether, we have so far analyzed material based on more than 20 hours of conversations with and among 17 speakers at the urban setting, members of 4 partially overlapping exchange networks and 20 speakers at the suburban setting, all of them members of an overlapping kinship network.
} 
been inhabited by members of the community engaged in agriculture. Later generations have turned to other professional domains, mostly being small time entrepreneurs and car mechanics. Agriculture has not been abandoned though, as older members of the families still have animals and farmland. Members of the grandparent generation, mostly men, have graduated from community primary schools. Members of the parent generation were the last to attend community primary schools, as these were abandoned after community education was de facto abolished in 1972. Most of them, including the father $(F)$ in our conversational data, graduated from technical/vocational state junior high-schools. The mother $(\mathrm{M})$ in our data spent part of her childhood in Turkey and graduated from primary school there.

In contrast to members of the older generations, children generation in our data, as well as the vast majority of the younger members of the community nowadays, attend monolingual state schools and graduate senior high-schools (Lyceum) or Technical/Vocational schools. All younger speakers in our data have either graduated from (D1, D2) or still attend a state senior high-school (D3, FR). The older daughter (D1) has also graduated from a Vocational Training Institute and at the time worked as an assistant pharmacist.

Excerpts 1-5 and 8-10 comprise conversations among members of the suburban network who belong to the grandparent, parent and children generations. The grandmother $(\mathrm{G})$ is in her mid-sixties. The parents are between 42 to 45 years of age, the mother being a housewife and the father a small time entrepreneur. The children participants are the three daughters/sisters of the couple, aged 16 (D3), 18 (D2) and 20 (D1), and a 15 year old boy, distant relative of the family (FR), whom we have named Ercan). The fourth child of the couple, the 16-year-old twin brother of the younger daughter is not present at the event. All participants are members of the same close-knit neighbourhood community network.

The particular network our informants form part of is defined as close-knit, based on the fact that families in the settlement live close together, are interconnected as members of an extended family network, are in everyday contact and share leisure time activities such as visiting each other during the day for "a cup of coffee" - without prior arrangements. Doors practically remain open during the day and people feel free to visit each other almost any time. In the conversational data discussed in the present study, much of the discussion revolves around Ercan's birthday party to which even older members of the network have been invited.

Excerpts 6 and 7 are instances of bilingual family conversations coming from another two families residing in the city of Rhodes that were discussed elsewhere (Georgalidou, Kaili and Celtek 2008). Both excerpts come from 
family gatherings which are attended by Father, Mother and Son. They are discussed as prototypical — as opposed to non-prototypical — instances of the code alternation patterns discussed in the literature.

\section{The analysis ${ }^{7}$}

\subsection{The prototypical case of code alternation: The discourse organizational alternation}

Pattern I: From code A to code B, between utterances or in the same utterance; discourse related alternation/code alternation as a contextualisation cue (Gumperz 1982; Auer 1995; 1998).

\section{Excerpt 1}

Participants: F=Father, $M=$ Mother, $D 2=2^{\text {nd }}$ Daughter

Setting: Just before Ercan joins the family for dinner

$01 \mathrm{~F}$ : Yemekli mi yapçek bu yaşgününü? ((Referring to Ercan’s birthday party))

02 D2: Yemekli yapçekmiş.

$03 \mathrm{M}$ : Doğru mu söylüyorsun?

04 D2: Yemek yime de gel dedi bene, sordum= M: ((laughing))

$\rightarrow 05$ D2: =Na fao ke na rtho i na mi fao ipa. O da dedi yimeden gel. Opote.

$01 \mathrm{~F}$ : Is he going to serve food on his birthday? ((referring to Ercan's birthday party))

$02 \mathrm{D} 2: \mathrm{He}$ is going to serve food.

$03 \mathrm{M}$ : Are you telling the truth? ((Really?))

04 D2: He told me to come without having eaten= M: ((laughing))

$\rightarrow 05$ D2: =Should I eat and come or not I said. He told me come without having eaten. Therefore.

The first example (excerpt 1) is a typical case of discourse organizational codeswitching. The inter- (turns 04-05, by the same speaker- D2) and intra-turn

\footnotetext{
7 We analyze excerpts of a family dinner conversation that form conversational episodes that can be discussed as units of talk within on-going interaction, that is, sequences introducing and often sustaining a frame that is bounded by talk and activity devoted to other matters (Lytra 2007: 76). A loose English translation of the Greek/ Turkish conversations is given.

Symbols used in the transcription: -: self-repair, //: interruption, (.): pause, (()): extralinguistic information, underlined segments: speaker emphasis, =: latching, []: simultaneous speech, (): unintelligible segment, $\uparrow \downarrow$ : rising or falling intonational shift, . a full stop indicates a stopping fall in tone, , a comma indicates continuing intonation, ? a question mark indicates rising inflection.
} 
switching in the $5^{\text {th }}$ turn contributes to the construction of direct-reported speech (Schiffrin 1996) in the context of the reporting of an incident relevant to the present discussion, i.e. the arrangements made for Ercan's birthday party. It contextualizes the voices of different speakers, Ercan's and the narrator's, who switches to Greek to report her own contribution to a discussion previously held with Ercan. The contrast between languages is not indicative of variable language preferences of the speakers as this can be seen in the overall organization of this particular dinner conversation. Also, the second switching in turn 05 marks the boundaries of the reported chunk, and invites participants to draw their own conclusions as to Ercan's intentions.

\section{Excerpt 2}

Participants: $M=$ Mother, $G=G r a n d m o t h e r, ~ D 2=2^{\text {nd }}$ Daughter, FR=Ercan

Setting: During dinner

$01 \mathrm{M}$ : Ercan annemi çă̆ırdın mı? (2") Anne, seni çağırdı mı?

02 D2: A:, anne çocuk kimi isterse- Istersen şeyi de çağırırsı Ayşe ablayı da?

03 G: Oynuyom da ben.

04 FR: Ne oynuyon?

$05 \mathrm{M}$ : çaça oynuyo.

$\rightarrow 06$ FR: Ben onu bilmiyom ben. Ego ksero kati pop eki.

$07 \mathrm{M}$ : Ayşe ablayı çağırdın mı?

08 FR: Hangini?

((They are all laughing))

09 FR: Dur bakalım, çağırdımdı.

$10 \mathrm{M}$ : çağırdın mı?

11 FR: Annem çağırdı, sormadan yapmadan çağırıyo şeyleri.

12 D2: Ayıp de me Ercan?

$\rightarrow 13$ FR: Ma ksero go $\uparrow$

$\rightarrow 14$ D2: Pes ta re Ercan^ ((A greek expression showing profound agreement with the previous statement))

01 M: Ercan have you invited my mother? (2") Mother, has he invited you?

02 D2: A:, Mother, the child, whomever he wants/ Do you want him to invite even aunt Ayse?

03 G: I can also dance.

04 FR: What do you dance?

$05 \mathrm{M}$ : She dances cha-cha.

$\rightarrow 06$ FR: I don't know what this is, I. All I know is some pop dance.

07 M: Have you invited aunt Ayse?

08 FR: Who?

((They are all laughing))

09 FR: Let me see, I have invited her.

$10 \mathrm{M}$ : Have you really invited her?

11 FR: My mother has invited her, she invites people without asking ((me)).

12 D2: Shame, isn't it Ercan? 
$\rightarrow 13$ FR: I bet it is

$\rightarrow 14$ D2: Just say so Ercan^ ((A Greek expression showing profound agreement with the previous statement))

In the second example, (excerpt 2) conversation also revolves around arrangements made over Ercan's birthday party, namely the people invited to it. The humorous/teasing frame is constructed through incongruities based on the contrast between a 15-year-old boy's birthday party and a possible guest list comprising people who belong to older generation groups. In turn 1 , Mother asks Ercan whether he has invited her mother (who is over 65) to his party. Mother's question is constructed as "a rather exaggerated version of the proposed action" making apparent that it is not intended as a real suggestion (Drew 1987, 232). Along the same line, D2 takes the floor, instead of Ercan who actually never gets the chance to contribute a second pair part to the adjacency pair initiated by Mother, to question her mother's right to interfere with somebody else's guest list. Her attempt to claim the floor so as to seemingly "defend" Ercan's rights, by initiating an insertion sequence challenging her mother's attempt to make Ercan invite her own mother to his party, is cancelled by the second part of her contribution where the name of another elderly potential guest is introduced. Subsequent to another series of turns that form a second insertion sequence (turns 03-06), Mother reinitiates her daughter's remark concerning aunt Ayse, in the form of a question as to whether she has actually been invited to the party. After establishing that she has, by Ercan's mother without letting him know, D2 negatively comments on the procedure maintaining Turkish as the medium of the interaction (turn 12). In a serious rather than teasing frame though, Ercan switches to Greek to emphasise agreement with her (turn 13) on which she further elaborates by also switching to Greek. Their medium choice reinforces the contrast between the procedure of inviting people to Ercan's party held so far and the rights of Ercan himself to make his own guest list. It also serves as a marker of realignment of the younger members of the group on the part of D2.

As far as the second insertion sequence is concerned, in turn 03, Grandmother claims the floor to contribute a playful assertion over her dancing abilities. All three women participants to the episode seem to be co-initiating the playful frame to which Ercan responds rather seriously, as if ignoring the incongruity aspect of their contributions. He responds by asking Grandmother what she can dance, a question answered by Mother with another humorous assertion that she can dance cha-cha, which is in obvious contrast with what a person of her age can actually do. To this, Ercan, who does not seem to adopt the teasing frame throughout the conversation, responds by stating that he doesn't know what "cha-cha" is, immediately followed by a switch to Greek to assert that all 
he knows is some pop dance. Code-switching in turn 06 therefore, contributes to the construction of opposition between the things the speaker does or does not know. As the comment is addressed to Mother, it is initiated in Turkish, the language preferred by all adult speakers in the event.

As far as the humorous frame is concerned, jab lines systematically targeting Ercan, contribute to the construction of his identity as a young partner to the event. His lack of response in an equally playful manner also reinforces his status not only as a guest, who would not risk involvement in "an inherently ambiguous activity that can produce uncertainty in talk" (Lytra 2007, 100), but also as a young person addressing his adult hosts. At the same time though, the humorous "attacks" contribute to the construction of a "collective pleasurable sociability" (Lytra 2007, 206), as well as the sense of closeness and ingrouping, as the person targeted does not reject teasing attempts by others (Archakis and Tsakona 2005). The switching to Greek on the part of the younger members of the group also reinforces the contrast of young versus adult.

\section{Excerpt 3}

Participants: $M=$ Mother, D1 $=1^{\text {st }}$ Daughter, D2 $=2^{\text {nd }}$ Daughter

Setting: Sometime before dinner begins

$01 \mathrm{M}$ : Sizde ne kadar eczanede?

02 D1: Ena trianda.

$03 \mathrm{M}$ : Biz ne kadar aldık şimdi?

04 D1: Ena peninda.

$05 \mathrm{M}$ : Sizde daha ucuz yani?

06 D1: İkosi lepta.

07 D2: [Mono?]

$\rightarrow 08 \mathrm{M}: \quad[\mathrm{E}: \uparrow]$ ikosi lepta ikosi leptadır.

$01 \mathrm{M}$ : How much is it at your pharmacy?

02 D1: One thirty.

$03 \mathrm{M}$ : How much have we bought it now?

04 D1: One fifty.

$05 \mathrm{M}$ : Is it cheaper at you ((your pharmacy)) that is?

06 D1: Twenty pence.

07 D2: [Only?]

$\rightarrow 08 \mathrm{M}: \quad[\mathrm{E}: \uparrow]$ twenty pence is ${ }^{8}$ twenty pence.

Excerpt 3 structurally resembles pattern II code alternation practices (see 4.2), as languages are alternated repeatedly until all partners switch to one common

8 'is' in Turkish is usually indicated by a zero morpheme $\{\varnothing\}$. The suffix -DIr is attached to the noun mainly when the described event is emphasized. 
medium (turns 06-08). Nevertheless, unlike the participant related codeswitching, (or the medium negotiation switching), Mother switches to Greek in turn 08 , the final turn of the episode, to mark her disagreement with D2's evaluative rhetoric question insinuating the insignificance of such a small amount of money (turn 08). Mother's turn echoes, via repetition, D1's contribution in turn 06. She chooses to construct her unit via a figurative expression (a tautology that produces the implicature of disagreement) which functions as an assessment summary and a topic closing device (Drew and Holt 1998). The code mixing structure produced by the use of the Turkish epistemic copular $-\mathrm{DIr}^{9}$ at the end of the sequence further reinforces the interpretation of the lack of a base language as the overall medium of the conversation. Speakers of different age groups maintain their preferred language, and language choice convergence or consensus does not seem to be an issue as far as the participants to this event are concerned (also see 4.3), a fact that raises issues over the principle of same medium talk preference (Gafaranga 2007a, 305).

\section{Excerpt 4}

Participants: $\mathrm{M}=$ Mother, $\mathrm{FR}=$ Ercan

Setting: Towards the end of the dinner event

$01 \mathrm{M}$ : Yarın hangi dersi yazıyorsun?

02 FR: History.

$\rightarrow 03$ M: Vay vay. Istoria tis zois su e:? Ande

$01 \mathrm{M}$ : Tomorrow which course are you writing? ((taking exams))

02 FR: History.

$\rightarrow 03$ M: Vay vay. The history of your life isn't it? Come on $\downarrow$ ((your life story))

Excerpt 4 is another instance of the playful frame of the interaction as a whole, constructed by the humorous jab line targeting Ercan in turn 03. Mother/ hostess chooses Turkish to ask Ercan about the following day's exam. He answers in English (one word loans often used by young language users, Jørgensen 2005). Similarly to excerpt 3, Mother resorts to a Greek figurative expression to mark the closure of the sequence (turn 03). She initiates her turn with a Turkish marker of (in this case) playful despair and then switches to Greek to take advantage of the incongruity created by the ambivalent meaning of the word "history" i.e., history/a school subject, history/a story, a narrative (Attardo 2001). Note that during this dinner gathering, Mother only

\footnotetext{
9 Turkish is subject to rules of vowel harmony and consonant alternation due to assimilation. Where both the consonant and the vowel are subject to alternation, the alterable sounds in a suffix are indicated by capital letters. -DIr here stands for the following 8 possible allomorphs: -dir, -dır, -dur, -dür, -tir, -tır, -tur, -tür.
} 
switches to Greek twice, and that, in this case, the humorous effect could not have been achieved in Turkish due to different lexicon. Again, looking at the overall structure of this particular conversation, Mother contributes to the construction of youth identities by humorously targeting Ercan as a rather negligent school student.

\section{Excerpt 5}

Participants: F=Father, $\mathrm{M}=$ Mother, $\mathrm{D} 1=1^{\text {st }}$ Daughter, FR=Ercan

Setting: During dinner

$01 \mathrm{~F}: \quad$ Ercan $\uparrow$

02 FR: Hm?

03 F: Bak. Şu mezeden acık al. Kokumluk. Dene len dene.

$04 \mathrm{M}$ : Utanma bak utanma.

05 F: Hani sofrada ekmek?

$06 \mathrm{M}$ : Ekmek nerde?

$\rightarrow 07$ FR: Aka istemiyom ekmek.

08 D1: A signomi exume patates den kani

09 F: Kızım iki dilim kesin ekmek.

10 D1: Ohi.

$\rightarrow 11$ FR: Bişey olmaz tamam.

$01 \mathrm{~F}: \quad$ Ercan $\uparrow$

02 FR: Hm?

03 F: Look. Take some of this delicacy. Take a bite. Just try it, you.

$04 \mathrm{M}$ : Don't be shy, don't be shy.

$05 \mathrm{~F}$ : Where is the bread on the table?

$06 \mathrm{M}$ : Where is the bread?

$\rightarrow 07$ FR: No I don't want bread.

08 D1: A, I'm sorry, we are having potatoes, it's not right.

09 F: My daughter cut two slices of bread.

10 D1: No.

$\rightarrow 11$ FR: It's ok no problem.

In excerpt 5, medium choice is connected to the marking of dispreferred sequences ${ }^{10}$. Rejecting the offer of food by both his host and hostess

${ }^{10}$ Contrary to the choices made in excerpt 5, the following example (Georgalidou, Kaili and Celtek 2008) is a typical instance of Pattern I code alternation in order to mark a dispreferred sequence. The excerpt is part of a conversation coming from a city family dinner event, the participants being an elderly couple and their 30-year-old son. Switching codes in this excerpt is used by Mother to mark the dispreferred sequence of rejecting the indirect request of the son to switch to a different TV channel (turn 02), in turn 03 .

Excerpt 6

Participants: $\mathrm{M}=$ Mother, $\mathrm{S}=$ Son

Setting: Family dinner- Urban network 
(turns 03, 04), Ercan uses their preferred language - but not his (see section 5), a choice that functions as redressive action (turns 07, 11). In Brown and Levinson's terms (1987: 69-70) redressive action "gives face" to the addressee, that is, it attempts to counteract the potential face damage of a Face Threatening Act (FTA). In CA terms, rejections, being potentially dispreferred sequences (Davidson 1984; Pomerantz 1984), call for extra conversational work towards the management of possible damage, in this case achieved through preservation of the addressees' preferred code ${ }^{11}$. What is more, the use of same language to mark the dispreferred sequence in excerpt 5 is in sharp contrast to the choice made in excerpt 6 (see footnote 4), in which Mother alternates codes to mark the dispreferred action of rejecting a request. The variable status of the speakers, guest versus family member, is in accordance with their choice of medium. On the contrary, the marking of disagreement and rejection as a non-dispreferred sequence is done through switching to Greek by the older daughter of the family (turns 08,10 ). D1 switches to Greek, the overall preferred language by the younger members of the group, to reject her father's request for bread (turns 08,10 ). In this case opposition and disagreement do not necessarily count as dispreferred choices (Kakava 2002; Williams 2005), as in conversations among family members challenges can also mark a playful frame. What is more, in some cultures, including Modern Greek, disagreement can be considered as a form of sociability that reflects solidarity and serve as a ritualized form of opposition (Kakava 2002, 1540). The interpretation of the actions done in turns 08 and 10 as non dispreferred is reinforced by the overall playful frame of this particular family dinner conversation.

01 M: Ti tha kanun afti?

02 S: Ego pali leo na dume ligo ti ginete ston kozmo.

$\rightarrow 03$ M: Dur bakalım bu lahanayı ne açıyor böyle, içine ne dolduracak?

$01 \mathrm{M}$ : What are they going to do? (watching a programme on Turkish TV)

$02 \mathrm{~S}$ : I, on the other hand, say that we'd better see what is going on in the world. (indirectly requesting a switch to a Greek channel to watch the news)

$\rightarrow 03 \mathrm{M}$ : Wait a minute. Let us see why he is opening this cabbage like this, what is he going to stuff it with?

11 Whether positive or negative politeness is at work in excerpt 5 raises interesting questions over the usefulness of clear-cut distinctions among negative and positive politeness strategies, the former expressing linguistic deference, and the latter enhancing in-grouping and solidarity (Brown and Levinson 1987, 69-70). As both aspects of a person's face can be addressed simultaneously (Bayyurt and Bayraktaroglu 2001), by using the addressees' preferred language, Ercan seems to be both expressing linguistic deference as well as to be marking in-group belonging. Such an analysis of ambivalent strategies for the management of face threatening acts, or else, dispreferred sequences, raises important issues concerning Politeness theory that exceed the scope of this paper. 


\subsection{The language preference related switching}

PatTern II: From code A to code B repeatedly, until consensus is reached as to the medium of the exchange; the language preference related switching (Auer 1995) or the case of medium negotiation (Gafaranga 2007a).

\section{Excerpt 7}

Participants: F=Father, $S=$ Son

Setting: Chatting among family members- Urban network

$01 \mathrm{~F}$ : Orda sivrisinek mi var olan?

$02 \mathrm{~S}: \mathrm{Ne}$.

03 F: Git elinne vuruver.

04 S: Ooh. Fere mia pandofla.

05 F: Git, elinne vur da, git elini yıkıver. (7”) Hiç sillogodan, hiç geçmiyon mu?

$06 \mathrm{~S}:$ An vrune kati, tha mu pun afti.

$\rightarrow 07$ F: Perna ke si pes kalimera, de hanis tipota, afto mu ipe ke o Ali., 'na lei lei 'kalimera, otan ke me vlepi' lei 'a mu pi, a rti konda mu' lei 'na sizitisume.'

08 S: Pios to pe afto?

09 F: Aftos to pedaki 'Thelo' lei 'Etsi na anihti' lei.

10 S: Pu mexeri ma aftos?

$01 \mathrm{~F}$ : Is this a mosquito over there?

02 S: Yes.

03 F: Go and hit it with your hand.

04 S: Ooh. Go get a slipper.

05 F: Hit it with your hands, then go, wash your hands (7”). Don't you ever stop by the association?

$06 \mathrm{~S}:$ If they find out something, they will let me know.

$\rightarrow 07$ F: Just stop by and say "good morning". You have nothing to lose. This is what Ali told me.

08 S: Who said this?

$09 \mathrm{~F}$ : He this guy, 'I want him to open up' he says.

$10 \mathrm{~S}:$ How come that he knows me?

Excerpt 7 is part of a conversation among members of family in the city network. It is also a typical case of pattern II code alternation in which consensus is sought over the medium of the interaction. In this particular excerpt, after repeated switching from Turkish to Greek by Father and Son (turns 01-06 successively), the son, a graduate of a Greek university in his early twenties, finally prevails in the language negotiation process and the father switches to Greek (turn 07). The switching does not mark other conversational phenomena as a shift in topic has already taken place in turn 05 . What is more, Greek remains the medium of interaction for the rest of the episode. 


\section{Excerpt 8}

Participants: F=Father, G=Grandmother, D3=3 $3^{\text {rd }}$ Daughter, FR=Ercan

Setting: Towards the end of the dinner event

01 D3: To idio imaste? ((teasing him))

02 FR: To idio imaste. Gia ena perissotero mathima pu grafis? Gia dio ande?

03 D3: Ego avrio grafo dio mathimata.

04 FR: Ti grafis?

05 D3: Agglika ke pliroforiki.

06 FR: İdes? (2") Emis olo k'olo mones ehume.

$\rightarrow 07$ G: Azcık çocuğum Türkçe konuşun da, Türkçe öğrenin//

$\rightarrow 08$ F: Çocuklar//

$09 \mathrm{G}$ : Öğrenin.

((After the children had gone on in Greek for a few more turns))

10 G: Öğrenelim de gonuşalım bile demiyorlar. Biz- Ama:n^

$11 \mathrm{~F}$ : Yarın- yarın para vercekler dillerini öğrenmeye.

12 FR: Ela a su po.

$\rightarrow 13$ D3: Ela a mu pis. Türkçe konuş.

01 D3: Are we the same? ((teasing him))

02 FR: We are the same. For one course you are writing more ((taking exams))? Two at most?

03 D3: I am writing ((taking exams)) two courses tomorrow.

04 FR: What are you writing? ((taking exams))

05 D3: English and computer science.

06 FR: You see? (2") We are only taking exams on the odds. ((odd days, like Tuesday and Thursday))

$\rightarrow 07$ G: Just a little my child, speak Turkish, to learn Turkish//

$\rightarrow 08$ F: Kids//

09 G: To learn

((After the children had gone on in Greek for a few more turns))

10 G: They do not even say to learn and speak. We-Ama:n^

$11 \mathrm{~F}$ : Tomorrow- tomorrow they will pay to learn their language.

12 FR: Come here to tell you ((something))

$\rightarrow 13$ D3: Come here to tell me ((something)). Speak Turkish.

Excerpt 8 is again a case of participant related code-switching, but unlike the previous one, which is a typical instance of Pattern II code alternation, the language negotiation process is a straightforward one. Grandmother, who has not been participating in the children's prior conversation so far, takes the floor in turn 07 to directly order the children to use Turkish in order to learn the language. Father is in alignment with Grandmother, as in turn 11 he constructs a we-identity based on the framing of Turkish as their, i.e. the children's rightful language. After several turns of parallel conversations, D3 complies with them as, in the middle of turn 13 , she switches to Turkish with a bald 
on-record directive to her partner to use Turkish. Excerpt 8 differs considerably from excerpt 7 as medium negotiation is done directly and medium selection (Torras and Gafaranga 2002; Gafaranga 2007a) is not the outcome of a symbolic verbal duel in which language preference of different participants is indirectly indicated by their choice of medium. D3 switches to Turkish as a result of being directly instructed to do so by the elderly participants in the event who exercise their right to instruct the younger members of their family as to what they consider proper linguistic behaviour. In this excerpt, the contrast between young and older generations of speakers also becomes manifest.

\subsection{The choice of a bilingual medium}

PAtTern III: Turn internal switching between languages so that no single language can be identified as the base language; keeping language choice open or the choice of a bilingual medium as part of the overall organization of talk (the monolectal view of code-switching, Meeuwis and Blommaert 1998; Auer 1998; Gafaranga 2007a).

\section{Excerpt 9}

Participants: F=Father, $M=$ Mother, D2=2 $2^{\text {nd }}$ Daughter, FR=Ercan

Setting: During dinner

01 F: Ercan kuru kuru içilmez. Bi tane çatalla azcık yemek //

$02 \mathrm{M}$ : Yemek koyem.

03 FR: A, istemiyom, istemiyom. Yidim ben.

$04 \mathrm{M}$ : Ne Yidin?

05 FR: Evde pitsa yidim//

06 M: Pitsayı kim yapıyo?=

07 FR: =Kafe ipia.

08 F: Len annen yemek yapmıyo mu? Oluyo mu böyle pitsa bira, pitsa bira?

09 FR: Ma ksero go^ Şey, edo ke mia vdomada pitsa yiyok.

All: ((laughing))

10 FR: İhame kolisi sto- şeye stáagga. Tora- Yani, omeletala, hani şe oluyo- Ohi omeletaNası? İçine //

$11 \mathrm{M}:$ Krepa mi?

12 FR: Hayır.

13 D2: Me lahanika? Kabaklan?

14 FR: Lukaniko gibi hani bişe.

15 D2: Sucuk?

16 FR: Ha sucuk

17 D2: E: ondan mi?

18 FR: Ondan. İhame kolisi safto. Kathe ke mia mera sucuk. E: leo, den pai allo, as alaksume. 
$01 \mathrm{~F}:$ Ercan you cannot just drink. With a fork, some food//

$02 \mathrm{M}$ : Shall I serve?

03 FR: Ah, it's ok, it's ok. I have already eaten.

$04 \mathrm{M}$ : What did you eat?

05 FR: I ate $p i z z a$ at home//

$06 \mathrm{M}$ : Who made the pizza?=

07 FR: =I had coffee.

08 F: Hey doesn't your mother cook? What is this pizza beer, pizza beer?

09 FR: See $\uparrow$ Well, for a week now we have been eating pizza.

All: ((laughing))

10 FR: We were stuck-well to the eggs. Now- That is, with omelet, that is done- Not omeletWhat do you call it? Inside //

$11 \mathrm{M}$ : Was it pancake?

12 FR: No.

13 D2: With vegetables? With courgette?

14 FR: Something that looks like sausage.

15 D2: ((Turkish)) sausage?

16 FR: Ya ((Turkish)) sausage.

17 D2: E:, like this one?

18 FR: Like this one. We were stuck to that. Every single day ((Turkish)) sausage. E: I say,enough is enough, let us change.

Despite the fact that in certain cases pattern III code alternation has clear discourse functions (Auer 1984), in excerpt 9 this is not always the case. In similar conversational episodes the direction of the switches may be irrelevant, but the contiguous juxtaposition of languages may contextualize repair, shifts in topic, the introduction of narrative, topic-comment structures, reiteration for emphasis, rejections, as well as different types of semantic contrasts (Georgalidou, Kaili and Celtek 2008).

In excerpt 9, the alternation between languages does not always serve discourse functions (Pattern III, the Discourse Related Transfer, Auer 1984). What is more, the direction of the switches does not allow the selection of one of the languages of the interaction as the base language against which language alternation becomes meaningful (Auer 1984, 84; 1995, 126). Cases like this one are discussed in Bilingual Conversation Revisited (Auer 1998) as nonconsequential on the level of language choice. Along this line, the bilingual medium as an unmarked choice of the participants of this dinner conversation, is systematically used by the younger speakers of the group, and it contributes to the construction of youth identities as it contrasts with the choices made by grandmother and parents who use the local variety of Turkish systematically, with momentary/brief switches to either Greek or to the bilingual medium (see 4.4, transfers). 
More specifically, in excerpt 9 (similarly to excerpt 5) both Father and Mother take turns to offer food to Ercan (turns 01, 02) which he again rejects by means of his host and hostess-preferred language stating that he has already eaten (turn 03). In turn 04, Mother initiates a question/answer sequence asking Ercan what he has actually eaten. Ercan responds by means of the bilingual medium, as the word 'pizza', a loan word for both languages, is uttered with the Greek phonological pattern. Despite the fact that a closer analysis can reveal pragmatic functions in the case of moving from the general to the particular (turn 13) and self-initiating repair (turn 10), the overall organization of the excerpt, as far as the medium choice pattern that is at work is concerned, points to that of the bilingual medium. The same choice is maintained by all the participants in the rest of the talk. Adult speakers use momentary alternations or transfers in turns 06, 08 and 11 (also see 4.4), whereas Ercan constructs more structurally complex bilingual utterances as in turns 09 and 10 .

\section{Excerpt 10}

Participants: F=Father, $M=$ Mother, D2=2 $2^{\text {nd }}$ Daughter

Setting: During dinner

$01 \mathrm{~F}$ : Ercan akşam ne var programda? Ona göre.

02 FR: Programda çok şeyler var.

03 F: Ne var yani?

$04 \mathrm{M}$ : [süprizler mi var?]

05 D2: [ya na rthume analogos.]

06 FR: Dvd var, musiki exi dışarıda. [Biritses//=]

$07 \mathrm{M}$ :

[hadi yaa $\uparrow]$

08 D2:

$09 \mathrm{~F}:=$ Biritses?

[Opaâ]

FR ((laughing))

10 D2: Bravo $\uparrow$

$11 \mathrm{~F}$ : Mangal yancek mi?

12 FR: Bilmiyom onu bilmiyom. Onlar böyüklerin aralarında.

13 F: Ha baban evde olcek de me?

14 FR: Ne, kanonika.

$01 \mathrm{~F}$ : Ercan, what have you programmed for the night ((for your birthday night))? So that we have an idea.

02 FR: The program has many things.

$03 \mathrm{~F}$ : What has it got then?

$04 \mathrm{M}$ : [Are there any surprises?]

05 D2: [To come accordingly.]

06 FR: There will be dvds, there will be music outside. [Beer ((Plural- diminutive))//=]

$07 \mathrm{M}$ :

08 D2:

[That's great $\uparrow$ ]

[Great $\uparrow]$ 
$09 \mathrm{~F}:=\operatorname{Beer}(($ Plural- diminutive $))$ ?

FR: ((laughing))

10 D2: Bravo $\uparrow$

11 F: Will there be barbeque?

12 FR: I don't know, that I don't know. This is among the older people. ((This is something parents and older guests deal with- it is not the business of the younger guests))

13 F: Ha. Will your father be at home?

14 FR: Yes, sure.

The last excerpt discussed in this study (excerpt 10) is another example of the bilingual medium choice. Even though there is only one case of intrasentential switching (turn 06), both Turkish and Greek are used interchangeably and their juxtaposition does not necessarily serve discourse functions. Father initiates the episode by asking Ercan what he has programmed for his birthday party (turn 01). Ercan responds using Father's preferred language, and Father initiates another question/answer sequence by requesting more specific information on the things Ercan intends to do on his birthday. Both Mother and D2 take the floor simultaneously to elaborate on Father's question, the mother with a yes/no question as to whether there will be surprises at the party (turn 04) and the daughter with a justification as far as the request for details is concerned (turn 05). Mother preserves the medium used so far in the interaction but D2 switches to Greek, the language generally preferred in the interaction among members of the younger group. All three contributions may also be seen as co-initiations framing the playful attacks addressed to Ercan, a conclusion that can be drawn not only based on the obviously exaggerated version of a teenaged birthday party, but on the overall organization of this particular conversation.

Ercan finally gets the floor in turn 6 and cites the list of the things he has organized for the party by means of the bilingual medium. Both Mother and D2 applaud in Turkish and Greek respectively, and subsequent to that Father reintroduces part of Ercan's contribution in the form of a request for confirmation (turn 09). The teasing frame is further established by Father's choice to humorously question the drinking of alcoholic drinks at the particular event, i.e. a 15-year-old's birthday party. This turn echoing Ercan's response to his question, is the only case of him switching to Greek. The humorous/teasing frame is also contextualized by laughing as a response to his contribution. In the rest of the interaction Father switches back to Turkish whereas D2 and Ercan switch between languages, an unmarked choice that is similar to the one made in both excerpts of this section and in excerpt 3 presented in 4.1, again raising doubts as to whether preference for same medium talk is a crucial aspect of the organizational patterns of this conversation. 


\subsection{Transfers}

PatTern IV: Intrasentential momentary switches that do not change the language of the interaction: Participant related transfers (Auer 1995) or the Medium Repair and the Medium Suspension Pattern (Torras and Gafaranga 2002).

We will not expand on pattern IV here, but this is another debatable pattern as it raises the question of what counts as code or else medium as far as the language users are concerned. Contrasting cases, as momentary lapses of memory as to what a word is in the language of interaction, and systematic use of discourse markers or lexical items in the "other" language of the bilingual speaker have to be dealt with separately. The former has to do with either +/-lack of competence or stylistics, whereas the latter with the potential of a single bilingual medium (Auer 1998, 7; Meeuwis and Blommaert 1998). Also, the cases of Medium Repair and Medium Suspension are quite similar in terms of structure as they are momentary switches that are not consequential for the overall language/medium of interaction (Torras and Gafaranga 2002).

\section{Some quantitative evidence}

As seen in the following tables, ${ }^{12}$ medium preference of the participants in this conversation differs considerably in connection to the generation group speakers belong to. As far as the adult members of the group are concerned (Grandmother, Father, Mother), Turkish is the language they systematically use when addressing either each other or their children and Ercan (70/ 73 turns in Turkish, Table 1). On the contrary, when younger members of the group have the floor, they switch between Greek (54/ 117 turns in Greek)

Table 1. Language preference as exhibited by Mother, Father and Grandmother

\begin{tabular}{ll}
\hline Language used & Turns \\
\hline Turkish & 70 \\
Greek & 1 \\
The bilingual medium & 2 \\
Total & 73 \\
\hline
\end{tabular}

\footnotetext{
12. Tables in section 5 are included to illustrate the distribution patterns of medium choice by our informants. However, since the data used in the analysis are restricted to a one hour dinner conversation, we chose not to expand on a quantitative discussion of our findings.
} 
Table 2. Language preference as exhibited by D1, D2, D3 and FR (Ercan)

\begin{tabular}{ll}
\hline Language used & Turns \\
\hline Turkish & 41 times \\
Greek & 54 times \\
the bilingual medium & 22 times \\
Total & 117 \\
\hline
\end{tabular}

Table 3. Language choice patterns of FR (Ercan)

\begin{tabular}{llc}
\hline Types of turns & & Number of turns \\
\hline Responded to adult & in Turkish: & 18 \\
speakers & in Greek: & 12 \\
(2 $2^{\text {nd }}$ pair parts) & in the bilingual medium: & 2 \\
& in an English loan word: & 1 \\
Responded to peer & in Turkish: & 1 \\
speakers & in Greek: & 9 \\
(2 $2^{\text {nd }}$ pair parts) & in a bilingual medium: & 6 \\
Self-initiated turns & in Greek: & 7 \\
$\left(2^{\text {nd }}\right.$ pair parts) & in Turkish: & - \\
Total & & 56
\end{tabular}

and Turkish (41/ 117 turns in Turkish) and they also make use of what can be described as the bilingual medium (22/ 117 turns in the bilingual medium) (Table 2).

Another important aspect of medium choice patterns is the structure of the sequences in question. When children respond to sequences initiated by adults, they are inclined to use the adults' preferred language, i.e. Turkish. This is especially the case with Ercan (Table 3) who, not only has the inferior status of a teenager, but also that of a guest to the event having to work on the face consideration aspect of the interaction (Brown and Levinson 1987). This becomes particularly obvious in his variable medium choice in accordance to the age and status of the addressor.

As shown in Table 3, Ercan mainly responds to adult initiated sequences in Turkish (18/56 $2^{\text {nd }}$ pair parts in Turkish, whereas 12/ 56 in Greek), but he exhibits preference for Greek whenever he responds to his peer interlocutors (9/ $562^{\text {nd }}$ pair parts in Greek, whereas 1/ 56 in Turkish). What is more, he only uses Greek to introduce first pair parts (7/ $561^{\text {st }}$ pair parts in Greek, whereas $0 / 56$ in Turkish). 


\section{Conclusion}

As the excerpts discussed have demonstrated, bilingual talk in everyday family interaction raises a number of interesting issues both concerning the theoretical models for the analysis of such complex phenomena as code alternation, and the identity construction processes that well exceed ethnicity/etic categorizations.

As far as identity issues are concerned, looking at the overall picture of the family conversation discussed, it becomes apparent that the alternating use of the community linguistic resources does not only serve discourse organization functions or ethnic identity construction processes. Excerpts featuring younger members of the community especially show a clear shift between welthey codes, as Greek and the Bilingual Medium are used to construct youth identities, in contrast to the identities constructed by the adult members of the close-knit community network through consistent use of Turkish. What is more, the younger speakers in our data do 'being young' more than signalling participation in any discrete ethnic or cross-ethnic categorization. The adults, on the other hand, function as guardians of crucial aspects of the community identity as they, indirectly in most cases, lean towards a more extensive use of Turkish by systematically initiating turns in Turkish only.

Nevertheless, the use of Greek or the bilingual medium on the part of the children is not rejected by them. On the contrary, all three options comprise unmarked linguistic choices by all participants in the event with the exception of excerpt 8, in which Grandmother, the older and less competent in Greek member of the group, straightforwardly interferes with the children's language choice patterns. Teasing and humorous attacks, mainly addressed to the younger guest of the dinner gathering, also contribute to the construction of the discrete identities of younger and adult participants to the event. What is more, the humorous/teasing frames established by the hosts to the dinner serve as a marker of solidarity and in-grouping (Archakis and Tsakona 2005) through establishing a frame of "collective pleasurable sociability" (Lytra 2007, 206).

As far as the code alteration patterns discussed in the literature are concerned, code alternation of pattern I type has clear discourse functions. In the excerpts analyzed in 4.1, alternation is used to achieve "a contiguous juxtaposition of the semiotic systems" (Auer 1995) that contributes to the organization of discourse. It can be described therefore, as the Discourse Oriented Pattern. Patterns II, III and IV on the other hand, could be seen as more Participant Oriented Cases of code alternation. Pattern II, the overt or covert negotiation over Medium Selection, as in excerpts analyzed in section 4.2, 
is consequential for the overall organization of talk as it determines the medium of talk at least within the duration of a conversational episode. Pattern III, the potentially Bilingual Medium (section 4.3), is also consequential for the overall organization of talk as it determines the medium of talk but not necessarily in terms of "a base language" or even preference for same medium talk (Auer 2000; Gafaranga 2007a, 305). It is mostly a case of the alternating use of the bilingual medium, Greek, and Turkish in the same communicative episode that is neither negotiable nor repairable. This practice exceeds the limits of same medium preference as an interpretation scheme within bilingual conversation and leads to an extensive discussion of identity construction practices. Pattern IV transfers, or the Medium Repair and the Medium Suspension patterns, are non-consequential for the overall organization of talk. Both cases serve as momentary transfers from the medium of the interaction, as they do not alter the medium at least within the duration of a conversational episode.

All four patterns often co-occur in longer conversational episodes, involving speakers of different orientations as to the politics of language as well as speakers of variable competence in the languages/ mediums of the interaction. Bilingual conversation therefore, seems to be moving along a continuum of prototypical code alternation, in which participants orient to preference for one base medium-of-interaction, be it monolingual or bilingual, towards code alternation of a less prototypical kind, i.e. choices discussed in Pattern III which raise questions which need to be further explored as to what the interpretation schemes of bilingual conversation actually are. As a consequence, the analysis of both the structural and the identity construction aspects of the conversations discussed in this paper, point to the need for greater clarity of the proposed patterns of code alternation within a conversational analytic framework. At the same time, focus on the sequential development of actual talk-in-interaction, "helps to limit the possible imposition of the analyst's interpretations on the meanings of code-switching" (Wei 2005, 276), especially the ones equating "hybrid" language use to cross-ethnic identities (Auer 2005).

\section{References}

Archakis, Argiris and Villy Tsakona. 2005. Analyzing conversational data in GTVH terms: A new approach to the issue of identity construction via humor. Humor 18, 41-68.

Atkinson, J. Maxwell and John Heritage (eds.) 1984. Structures of social action: Studies in conversation analysis. Cambridge: Cambridge University Press.

Attardo, Salvatore. 2001. Humorous texts: A semantic and pragmatic Analysis. Berlin / New York: Mouton de Gruyter. 
Auer, Peter. 1984. Bilingual Conversation. Amsterdam: John Benjamins.

Auer, Peter. 1995. The pragmatics of code-switching: A sequential approach. In One speaker, Two Languages, ed. Lesley Milroy and Pieter Muysken, 115-135. Cambridge: Cambridge University Press.

Auer, Peter. 1998. Introduction: Bilingual Conversation revisited. In Code-switching in Conversation: Language, Interaction and Identity, ed. Peter Auer, 1-24. London: Routledge.

Auer, Peter. 2000. Why should we and how can we determine the base language of a bilingual conversation. Estudios de Sociolingüistica 1, 129-144.

Auer, Peter. 2005. A postscript: code-switching and social identity. Journal of pragmatics, 37 (3), 403-410.

Bayyurt, Yasemin and Arin Bayraktaroğlu. 2001. The use of pronouns and terms of address in Turkish service encounters. In Linguistic Politeness across boundaries: The case of Greece and Turkey, ed. Arin Bayraktaroğlu and Maria Sifianou, 209-240. Amsterdam/ Philadelphia: John Benjamins.

Blom, Jan Petter and John J. Gumperz. 1972. Social meaning in linguistic structures: Codeswitching in Norway, In Directions in Sociolinguistics: The ethnography of communication, ed. Dell Hymes and John J. Gumperz, 407-434. Holt, New York: Rinehart and Winston.

Brown, Penelope and Stephen Levinson. 1987. Politeness: Some Universals in Language Usage. Cambridge: Cambridge University Press.

Davidson, Judy. 1984. Subsequent versions of invitations, offers, requests, and proposals dealing with potential and actual rejection. In Structures of Social Action: Studies in Conversation Analysis, ed. J. Maxwell Atkinson and John Heritage, 102-128. Cambridge: Cambridge University Press.

Drew, Paul. 1987. Po-faced receipts of teases. Linguistics, 25: 219-253.

Drew, Paul and Elizabeth Holt. 1998. Figures of speech: Figurative expressions and the management of topic transition in conversation. Language in Society 27, 495-522.

Fishman, Joshua A. 2000 [1965]. Who Speaks What Language to Whom and When?" In The Bilingualism Reader, ed. Li Wei, 89-106. London: Routledge. Reprinted from: La Linguistique 2 (1965): 67-88.

Gafaranga, Joseph. 2007a. Code-switching as a conversational strategy. In Handbook of Multilingualism and Multilingual Communication, ed. Peter Auer and Li Wei, 279-313. Mouton de Gruyter.

Gafaranga, Joseph. 2007b. Talk in two languages. New York: Palgrave Macmillan.

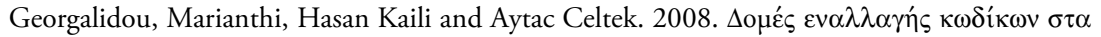

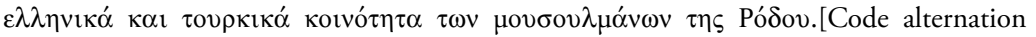
patterns of the bilingual in Greek and Turkish Muslim Community of Rhodes]. Studies in Greek Language: Language and Society, 125-137. Thessaloniki: Modern Greek Language Institution. Manolis Triandafilidis Institution.

Georgalidou, Marianthi, Vasilis Spyropoulos and Hasan Kaili. (forthcoming). Spoken varieties of Greek in the bilingual Muslim community of Rhodes. Proceedings of the $7^{\text {th }}$ International Conference of Greek Linguistics.

Gumperz, John J. 1982. Discourse Strategies. Cambridge: CUP.

Heath, Geoffrey. 1984. Language contact and language change. Annual review of anthropology $13,367-384$.

Jørgensen, J. Normann. 2005. Plurilingual conversations among bilingual adolescents. Journal of Pragmatics 37 (3), 391-402.

Kaili, Hasan, Vasilis Spyropoulos, Marianthi Georgalidou, and Aytac Celtek. 2009. Causative constructions in the Turkish variety of the bilingual Muslim community of Rhodes: A preliminary study. In Essays on Turkish Linguistics: Proceedings of the 14th International Conference on Turkish Linguistics, ed. Sıla Ay, Özgür Aydın, İclal Ergenç, Seda Gökmen, Selçuk İşsever, and Dilek Peçenek, 403-412. Wiesbaden: Harrasowitz-Verlag. 
Kakava, Christina. 2002. Opposition in Modern Greek discourse: cultural and contextual constraints. Journal of Pragmatics 34, 1537-1568.

Lytra, Vally. 2007. Play Frames and Social Identities: Contact encounters in a Greek primary school. Amsterdam: John Benjamins.

Meeuwis, Michael and Jan Blommaert. 1998. A monolectal view of code-switching: Layered code-switching among Zairians in Belgium. In Code-switching in Conversation: Language, Interaction and Identity, ed. Peter Auer, 76-100. London: Routledge.

Milroy, Lesley and Wei Li 1995. A social network approach to code-switching. In One speaker, Two Languages, ed. Lesley Milroy and Pieter Muysken, 136-157. Cambridge: Cambridge University Press.

Myers-Scotton, Carol. 1988. Codeswitching as indexical of social negotiations. In Codeswitching: Anthropological and sociolinguistic perspectives, ed. Monica Heller, 151-186. Berlin: Mouton de Gruyter.

Myers-Scotton, Carol and Agnes Bolonyai. 2001. Calculating speakers: Codeswitching in a rational choice model. Language in Society 30: 1-28.

Pomerantz, Anita. 1984. Agreeing and disagreeing with assessments: some features of preferred/ dispreferred turn shapes. In Structures of Social Action: Studies in Conversation Analysis, ed. J. Maxwell Atkinson and John Heritage, 57-101. Cambridge: Cambridge University Press.

Schiffrin, Deborah. 1996. Narrative as self-portrait: Sociolinguistic construction of identity. Language in Society 25, 167-203.

Torras, Maria Carme and Joseph Gafaranga. 2002. Social identities and language alternation in non-formal institutional bilingual talk: Trilingual service encounters in Barcelona. Language in Society 31 (4), 527-548.

Wei, Li. 1998. The 'why' and 'how' questions in the analysis of conversational code-switching. In Code-switching in Conversation: Language, Interaction and Identity, ed. Peter Auer, 156-179. London: Routledge.

Wei, Li. 2005. Starting from the right place: introduction to the special issue on Conversational Code-Switching. Journal of Pragmatics 37 (3), 275-279.

Williams, Ashley M. 2005. Fighting words and challenging expectations: language alternation and social roles in a family dispute. Journal of Pragmatics 37 (3), 317-328.

Winford, Donald. 2003. An Introduction to Contact Linguistics. Oxford: Blackwell. 